\title{
Analyze the Animal Model of Pruritus Based on Clinical Symptoms of Chinese and Western Medicine
}

\author{
Ya-juan WEN ${ }^{\mathrm{a}}$, Ming BAI and Ming-san MIAO ${ }^{\mathrm{b}, *}$ \\ Henan University of Chinese Medicine, Zhengzhou, 450006, China \\ awenyajuan1016@163.com \\ bMiaomingsan@163.com \\ ${ }^{*}$ Corresponding author
}

Keywords: Pruritus, Clinical features, Animal model.

\begin{abstract}
Objective: Based on the characteristics of clinical symptoms of pruritus, analyze the relevant animal model, and then propose the evaluation and improvement. Method: According to the clinical diagnostic criteria of pruritus in Chinese and Western medicine, summarize the characteristics and modeling methods of the current pruritus mode, and analyze the coincidence between the existing animal models and clinical features of pruritus. Result: At present, the animal model of mice, guinea pig itch is almost used, which reflects the pathophysiological characteristics of clinical pruritus. However, it is lack of disease model which can reflect the clinical characteristics of TCM. Conclusion: It is the focus of the future research to establish a better combination of symptoms and signs and the index system of pruritus model. Pruritus is a kind of disease of self-conscious itching and clinical primary lesions, only scratches, blood scab or hypertrophy of leather change, which belongs to the category of Chinese medicine "itching wind".The symptoms of Pruritus relates to invasion of the skin such as wind, wet, heat, turbid evil,when there are also due to blood deficiency caused by dry wind. Clinically, it can be divided into systemic pruritus and localized pruritus. It's Common symptom is severe itching, which can be seen in the whole body or confined to the anus, scrotum or genitals. It's paroxysmal and itchs sharply, which is often aggravated at night and affects sleeping. Scratch scratches, blood stasis appear if you scratch excessively.It appears eczema, lichen and pigmentation over time, which can be seen in a variety of skin diseases, biliary diseases, thyroid disease, kidney disease, cancer and AIDS and other common diseases. Pruritus has high incidence rate. Through the report which investigates 1236 cases of elderly subjects, we can find it's 827 cases which suffers from skin itching cured accounting for $67 \%$.Pruritus often affects the quality of life of patients, which leads to severe insomnia and then fatigue, fatigue, depression and even suicide. Modern research on pruritus has become the focus of medical research.
\end{abstract}

\section{Etiology and Pathogenesis of Pruritus}

\section{Pruritus Etiology and Pathogenesis of Modern Medicine}

Clinical medicine thinks that this disease is the allergic reaction caused by immune balance disorders, which may be related to the participation of several media such as histamine, 5- HT, neuropeptide, cell factor, Twenty alkanes, etc. The principle of treatment is to prevent secondary infection, reduce itching, promote healing, shorten the course of treatment, to avoid recurrence. The treatment of this disease includes antihistamine, sedative hypnotic and hormone therapy, although it can temporarily relieve itching discomfort but cannot cure itching. If medication for a long time, it 
appears other side effects, such as drowsiness, skin changes and changes in skin blood vessels, etc. There are difficulties in the clinical treatment of pruritus, while there is still no special efficiency. But often due to adverse reactions, it cannot be long-term application. After the treatment of intermittent, itching rapid recurrence, especially there isn't standard program about topical corticosteroids on children, so that the treatment of itching in children has become an urgent problem to be solved.

\section{Etiology and Pathogenesis of Pruritus}

Itch belongs to the category of Chinese medicine "itching wind". The symptoms of Pruritus relates to invasion of the skin such as wind, wet, heat, turbid evil, when there are also due to blood deficiency caused by dry wind. $<<$ Surgical treatment $>>$ writed that"Itch all whole body, no sore scabies, scratch more than" $<<$ The theory of Various pathogens $>>$ writed "The wind is itching, body by the wind, the wind into the striae, wrestle with blood gas, and all contacts in the skin. Evil micro, not the impact of pain, but the itch". Chinese medicine thinks that the pathogenic wind, dampness, heat evil, blood deficiency, insect prostitution and other main reason for the disease, the treatment should be based on dispelling wind and dampness, detoxification, nourishing and moistening, promoting blood circulation to remove blood stasis.

\section{Analysis of Clinical Features of Pruritus}

Generalized pruritus usually is often some systemic diseases such as diabetes, liver disease, visceral tumors, chronic renal insufficiency, thyroid dysfunction, habitual constipation, intestinal parasitic diseases, skin symptoms of autoimmune diseases and other diseases. It can also be caused by pregnancy, neuropsychiatric factors, spicy spicy food items, personal wear chemical fiber fabrics, climate change (hot, cold, wet, dry) and the working environment of biological or chemical substances caused by stimulation. The limitations of skin pruritus are not only related to the above factors, often by local factors such as epidermophytosis, pinworm disease, hemorrhoids, leucorrhea, sweaty clothes, friction induced local incentives etc.

Diagnostic criteria of modern medical eczema: $<<$ Academic of Chinese Clinical Dermatology >> (2009) writed by Zhaobian and <<Academic of Skin disease >> writed by Zhihua Wu. Clinical manifestation:(1)There was no skin rash except pruritus.(2) Due to severe scratching, scratches, swelling, erythema, scab, long pigmentation, moss or eczema like change.(3) broke out intermittently, aggravate at night.(4) In addition to itching, there is feeling of burning, ants. (5) Pruritus of the elderly, often with trunk itching.(6) Accompanied by headache, insomnia, depression, etc.

\section{Diagnostic Criteria and Clinical Manifestations of Pruritus in Western Medicine}

According to <new traditional Chinese medicine skin disease diagnosis of pruritus on TCM syndrome diagnostic efficacy standards promulgated in 2012, the State Administration of traditional Chinese medicine "and" reference Ouyang Heng editor, and Zhao Shanghua editor of < TCM dermatology > Chinese medicine clinical classification criteria for the diagnosis of pruritus are classified as follows. 
Table 1 Diagnostic criteria of Western medicine and laboratory examination indexes of pruritus

Clinical manifestation
Clinical manifestation (1) There was no skin rash except pruritus;
(2) Due to severe scratching, scratches, swelling, erythema, scab, long pigmentation,
moss or eczema like change;
(3) broke out intermittently,aggravate at night;
(4) In addition to itching, there is feeling of burning, ants;
(5) Pruritus of the elderly, often with trunk itching;
(6) Accompanied by headache, insomnia, depression, etc.
(1) Inflammation Index of Inflammation:Degree of Swelling
(2) Determination of capillary permeability:Area of dyeing Skin, The optical density of
the extracted tissue
(3) Index of itching behavior:Itch threshold, pruritus, duration of pruritus
laboratory
examination
(1) Hyperkeratosis and keratinization of the epidermis, edema and blisters in the cells,
thickening of the spinous layer, extension of the skin process, no blisters;
The
changes
(2) The dermal superficial capillaries were expanded or surrounded by lymphocytic
inflammatory cells, and collagen in the dermis increased slightly.

Notes:In line with clinical and laboratory tests for one were $6.2 \%$, in line with the biochemical indicators were 5\%; in line with Pathological changes were $15 \%$.

Table 2 diagnostic criteria for TCM Syndromes of pruritus

\begin{tabular}{|c|c|c|c|}
\hline $\begin{array}{l}\text { Dialectical } \\
\text { typing }\end{array}$ & The main symptom & Secondary symptoms & Tongue and pulse \\
\hline $\begin{array}{l}\text { Blood heat wind } \\
\text { syndrome }\end{array}$ & $\begin{array}{l}\text { (1) Itchy skin, bright red; (2) In the case of } \\
\text { hot, warm, cold, cold. }\end{array}$ & (1) Upset thirst; (2)Dry stool. & $\begin{array}{l}\text { Red tongue, thin yellow } \\
\text { fur, wiry pulse. }\end{array}$ \\
\hline $\begin{array}{l}\text { Blood stasis } \\
\text { syndrome }\end{array}$ & $\begin{array}{l}\text { (1) Itching in the waist, back, wrist; } \\
\text { (2) Scratch laden with purple streaks. }\end{array}$ & $\begin{array}{l}\text { (1)Dry mouth does not want to } \\
\text { drink; (2) Dull complexion(3)Mouth } \\
\text { lip color purple. }\end{array}$ & $\begin{array}{l}\text { Dark tongue or petechiae, } \\
\text { moss thin white, pulse } \\
\text { Sezhi. }\end{array}$ \\
\hline $\begin{array}{l}\text { Blood vacuity } \\
\text { engendering } \\
\text { wind syndrome }\end{array}$ & $\begin{array}{l}\text { (1) Dry skin, scratching the skin at the point } \\
\text { of thickening, scaly; (2) Long course of } \\
\text { disease, exacerbated by encounter. }\end{array}$ & $\begin{array}{l}\text { (1)Look tired;(2)Pale; } \\
\text { (3)Dizziness,palpi-tation,anorexia }\end{array}$ & $\begin{array}{l}\text { Pale red tongue, thin } \\
\text { white fur, pulse string. }\end{array}$ \\
\hline $\begin{array}{l}\text { The wind Sheng } \\
\text { itch syndrome }\end{array}$ & $\begin{array}{l}\text { (1) Itching of the whole body, no pain; } \\
\text { (2) Thickening of the skin, the skin like cattle } \\
\text { or collar; (3) With the break with the } \\
\text { collection, mostly dry tear. }\end{array}$ & $\begin{array}{l}\text { (1) Look tired;(2)Dizziness, } \\
\text { palpitation, anorexia. }\end{array}$ & $\begin{array}{l}\text { Red tongue, thin yellow } \\
\text { fur, wiry pulse. }\end{array}$ \\
\hline $\begin{array}{l}\text { Damp heat } \\
\text { syndrome }\end{array}$ & $\begin{array}{l}\text { (1) Itching is paroxysmal, more sudden onset; } \\
\text { (2) Severe itching, especially at night; (3) In } \\
\text { the vulva, anus and scrotum. }\end{array}$ & $\begin{array}{l}\text { (1) To catch every blood out of pain; } \\
\text { pain reduction. }\end{array}$ & $\begin{array}{l}\text { Red tongue, yellow greasy } \\
\text { moss, pulse string slide. }\end{array}$ \\
\hline
\end{tabular}

According to the clinical diagnostic criteria, the clinical manifestations of skin itching but no primary skin rash, often scratching appears exfoliation, after grasping blood scab, scratches etc. secondary damage. 


\section{Animal Model of Pruritus}

\section{Selection of Model Animals}

At present, the animal models can be used to create itch models, such as mice, rats, guinea pigs and rabbits. The application of the rat is less than that of the mice, but it is also found in the stimulation of skin inflammation, the central administration and the establishment of allergic conjunctivitis model. The guinea pig due to its own characteristics easily sensitized is widely used to establish the animal model of skin allergies, asthma and allergic conjunctivitis and other diseases, the sensitivity to histamine the histamine induced itch in animal models of choice. The rabbit skin is sensitive to the stimulation reaction, and the blood vessel permeability is also high. It is often used in the establishment of animal model of allergic itching and irritation of the skin. Mice, guinea pigs are cheap and easy to obtain, and skin tissue is similar to humans, the model can reflect the clinical features of pruritus is the most commonly used in the study.

\section{Animal Model and Analysis of Clinical Coincidence Degree}

Table 3 animal models of pruritus and clinical symptoms of Chinese and Western Medicine

\begin{tabular}{|c|c|c|}
\hline $\begin{array}{l}\text { Modeling } \\
\text { methods }\end{array}$ & Characteristics of animal model & $\begin{array}{l}\text { Consistent with the clinical features of Chinese and Western } \\
\text { Medicine }\end{array}$ \\
\hline $\begin{array}{l}\text { Dextran } \\
\text { induced Itch } \\
\text { model[8-11] }\end{array}$ & $\begin{array}{l}\text { Before the claw said scratching the head, } \\
\text { scratching and grasping the trunk, mouth bite } \\
\text { parts of the body as a sign of itching, the unit } \\
\text { time to record the frequency of itching and } \\
\text { itching in mice, in order to relieve the effect } \\
\text { of parity drugs. } \\
\text { The content of Ig E in serum decreased } \\
\text { significantly. }\end{array}$ & $\begin{array}{l}\text { Meet western medicine clinical symptoms(1)(2)(3)(6),pathologic } \\
\text { al change(1)(2), Biochemical index(1)(2) laboratory examination } \\
\text { (1)(2)(3),Coincidence degree } \geq 80 \% \text {; High degree of coincidence, } \\
\text { more application.Meet TCM Syndrom (2)(3), Coincidence de } \\
\text { gree } \geq 40 \%\end{array}$ \\
\hline $\begin{array}{l}\text { Histamine } \\
\text { induced itch } \\
\text { model }\end{array}$ & $\begin{array}{l}\text { In the presence of the guinea pig, the total } \\
\text { amount of histamine was given as the itch } \\
\text { threshold. The results of HE showed that the } \\
\text { proliferation of inflammatory cells. } \\
\text { Infiltration of.IFN-, IL-4 levels increased. }\end{array}$ & $\begin{array}{l}\text { Meet western medicine clinical symptoms(1)(2)(3)(6), pathologic } \\
\text { al change(1)(2)(3),Biochemical index(1)(3), laboratory examinatio } \\
\text { n(1)(2)(3),Coincidence degree } \geq 80 \% \text {; High degree of coincidenc } \\
\text { e,more application.Meet TCM Syndrome (1),Coincidence de } \\
\text { gree } \geq 40 \%\end{array}$ \\
\hline $\begin{array}{l}\text { 4-amino } \\
\text { pyridine } \\
\text { induced itch } \\
\text { mode }\end{array}$ & $\begin{array}{l}\text { Record the number of licking reactions in } \\
\text { the unit time. } \\
\text { Neutrophils were found in the inflammatory } \\
\text { cells of the tissue HE. }\end{array}$ & $\begin{array}{l}\text { Meet western medicine clinical symptoms(1)(2)(3)(6), pathologic } \\
\text { al change(1)(2),Biochemical index(1)(2)laboratory examination } \\
\text { (1)(2)(3) Coincidence degree } \geq 80 \% \text {; High degree of coincidence; } \\
\text { More application. } \\
\text { Meet TCM Syndrom(1)(2)(3),Coincidence degree } \geq 40 \%\end{array}$ \\
\hline $\begin{array}{l}\text { Compound } \\
\text { factor itch } \\
\text { model }\end{array}$ & $\begin{array}{l}\text { The scratch latency and scratching times } \\
\text { were recorded in thirty minutes, Each group } \\
\text { was injected into the skin of mice and the } \\
\text { histamine content in the skin was } \\
\text { determined.Neutrophils were found in the } \\
\text { inflammatory cells of the tissue HE. }\end{array}$ & $\begin{array}{l}\text { Meet western medicine clinical symptoms(1)(2)(3)(6),pathological } \\
\text { change(1)(2),Biochemical } \\
\text { examination(1)(2)(3), Coincidence degree } \geq 80 \% \\
\text { Meet TCM Syndrome(1)(2), Coincidence degree } \geq 40 \%\end{array}$ \\
\hline
\end{tabular}

The guinea pig pruritus model mice pruritus model and histamine phosphate induced by dextran induced the itch animal model, which is characterized in that the mouse paw said scratching head, after scratching scratching the torso, mouth parts of body etc. The results of HE showed that there were a large number of inflammatory cells infiltration in epidermis and dermis, epidermal thickening, hyperkeratosis and 
intercellular edema. The animal model of a particular species of spontaneous pruritus was more effective than the general model.

Accurate simulation of the pathophysiology of disease is a common animal model for the study of pruritus associated with a number of diseases. In order to avoid the discomfort caused by the animal model and the operation error, the experiment is more convenient and the result is more accurate. However, the specific species of animals, which can be used as animal models, are limited and the price is high, which limits the application of this model.

\section{Discussion}

At present, the pathogenesis of pruritus is less studied, mainly that itching is caused by the transmission of small nerve fibers, especially the unmyelinated nerve. Clinical evaluation of the degree of pruritus mainly using subjective evaluation methods, such as visual analog scale method (VAS), Because of the lack of language communication between humans and animals, this method is difficult to achieve in the evaluation of animal models. But the pruritus animal model can still be based on animal behavior or according to animal skin and nerve electrical activity evaluation. Most of the evaluation of the pruritus model using the former that is a certain period of time the number of animal scratch as the main evaluation index. In the process of recording the number of scratching the small magnet method to make the recording process easier and more accurate. In the establishment of the model of non - dose drug delivery, which is based on the symptoms of animal model, some indexes in the process of modeling, such as the number of times of administration and the total amount of drug delivery, can also be used as the index of evaluation. The itching reaction needs to be different from that of the pain response.

In the process of model making, the animal model of back itch was used. The model has a certain degree of clinical pathological characteristics of pruritus. Other itching models also have more applications. However, there is a lack of a systematic evaluation index system which can reflect the characteristics of TCM syndrome type. It is necessary to improve the modeling method based on clinical characteristics, and establish the animal model with TCM syndrome characteristics. Expand the relevant observation indicators, the development of appropriate instruments to check their behavioral changes. To provide a more suitable animal model for the prevention and treatment of eczema.

\section{Acknowledgements}

Supported by project grant from National "Eleventh Five-Year" support program (2008BAI53B09); Henan Province outstanding scientific and technological innovation team (TCJ2014-391); Zhengzhou Municipal Science and Technology Innovation Team Program (131PCXTD612).

\section{References}

[1].Ge Mengliang, Xie Zhihong, Zhang Chunling, et al.A case control study on 122 cases of simple senile pruritus.Chinese Journal of Pathology, 2006, 27(7):627-629

[2].Jiang Yansheng.Treatment of skin pruritus with Chinese Medicine.Chinese Journal of traditional Chinese medicine information, 2013, 20(6):93-94 
[3].Zuo Xiaohong, Wang Zehui, Lv Fan, et al.The skin pruritus and disharmony.Yunnan J Tradit Chin Med Mater Med, 2014,35 (8):92-93.

[4].Zhao B.Clinical dermatology [M].Nanjing: Jiangsu science and Technology Press, $2001,707$.

[5].Wu Zhihua.dermatology and venereology[M].Beijing: People's Medical Publishing House,2008,230-231.

[6].Yangheng Ou.New TCM dermatology [M].Beijing: People's military medical press, 2000, 294-295

[7].Zhaoshanghua.Dermatology of traditional Chinese Medicine [M].Beijing: Science Press, 2001, 168-170.

[8].Liu Hailong, Wu Guotai, Wang Ruiqiong,et al.Experimental study on the effect of Angelica sinensis and astragalus extract on experimental pruritus, Chinese Journal of experimental Traditional Medical Fomulae,2012,18(1):200-202.

[9].Li Ruiqi, Bai Ming, Miu Junxian, Miao Ming san.Effects of external application of clam shell oil paste on mouse eczema model and guinea pig pruritus model.Chinese Journal of traditional Chinese Medicine, 2013, 28(6):1699-1702.

[10].Zhao Le, Li Yanyan.Effects of Huangqi Guizhi Decoction five on -40 induced senile pruritus model AQP3 induced by D- galactose combined with dextran.Chinese Journal of experimental Traditional Medical Fomulae, 2015, 21(7):148-154.

[11].Zhang Haidi, Dong Yinmao,Meng Hong.he effects of Shu Minfang on allergic and pruritus model].Chinese Journal of experimental Traditional Medical Fomulae,2011,17(23):177-179. 